\title{
Response to Van Wee and Boarnet
}

\author{
Petter Næss ${ }^{\text {a }}$
}

\author{
Norwegian University of Life Sciences
}

\section{Introduction}

I am glad to see that there is considerable consensus about some of the main issues. Van Wee/Boarnet and I thus agree:

- that we know much about the relationships between residential location and travel. The causal mechanisms by which residential location influences travel behavior are mostly well-understood theoretically and empirically well-documented, although basic scientific inquiry requires additional studies

- that transport-related residential self-selection is in itself a demonstration of the influence of residential location on travel behavior

- that travel attitudes are not necessarily antecedent to choices of residential location but may themselves be influenced by residential location

- that activity preferences may be just as important as travel preferences in attitude-based residential self-selection

- that travel attitudes are not the most important criteria of residential preferences, and that several constraints can prevent people from realizing what they would otherwise prefer.

I agree with Van Wee and Boarnet that nihilist statements that we know nothing due to residential self-selection do not so much appear in the scientific literature on this topic as in the popular commentary on that literature. I think, however, that the researcher community has a responsibility for countering such arguments in the popular commentary on the research literature on residential self-selection. Unfounded nihilist statements on the topic are also sometimes reproduced in professional journals within planning, and probably also in scientific planning journals that do not have relationships between land use and transport as their core field of interest. Unless being countered in these forums, there is a risk that the academically sound interest in getting to the bottom of the role of attitude-based residential self-selection within the nexus of land use-travel interaction is being hijacked by anti-planning and prosprawl advocates (e.g., see Bruegmann 2005; O’Toole 2012).

I also agree with Van Wee and Boarnet that basic scientific inquiry requires additional studies, including inquiry into attitudes, moving patterns, and self-selection. Otherwise I would not myself have continued to investigate these issues. Residential self-selection will be an important part of a recently started study of residential location, travel, and health in the largest Norwegian urban regions, where my Norwegian colleagues and I are cooperating with one of the leading American scholars dealing with these issues (Jason Cao). This study also involves before-and-after studies among recent movers.

I furthermore agree with Van Wee and Boarnet that while the basic causal mechanisms by which residential location influences travel are quite well understood per se, it is still desirable to get as clear picture as possible of their magnitude in different contexts. This will enable planners to have more

apetter.nass@nmbu.no

Copyright 2014 Petter Næss

Licensed under the Creative Commons Attribution - NonCommercial License 3.0. 
realistic expectations of what travel behavioral effects may be achieved through the pursuit of different land use policies, such as inner-city densification, polycentric "decentralized concentration," or lowdensity urban expansion. Such estimates will need to be based on an adaptation of experience on the magnitude of these effects from case studies in different cities and urban contexts. The richer and more accurate the bulk of evidence from such studies, the better will planners be able to assess the travel behavior impacts of alternative land use policy options. Experience from a wide range of cities and metropolitan areas is necessary to enable a planner in a given city to draw on a study from a comparable urban context, whereas high accuracy in the effect estimations of each case study is necessary to ensure that the elasticity figures drawn on represent the reality of the case study city as correctly as possible. Each city is nevertheless unique (in terms of its combination of, for example, population size, affluence level, composition of trades, existing built environment, location of jobs and other trip destinations, and natural topographic conditions), and the existing empirical evidence may be from recent or older studies. The adaptation of elasticities from studies undertaken earlier and elsewhere to a specific planning situation must therefore necessarily be based on qualitative judgment and cannot purport to be very exact.

I can only support Van Wee and Boarnet in their statement that people might choose to travel over longer distances, despite the disutility of travel, because of the valuation of the activity (compared to the valuation of a nearer activity) and that "accessibility benefits" may more than compensate for the disutility of longer travel times. This is one of the main points in my own research. As mentioned also in the Tempest in a Teapot paper, the implication is that daily-life travel behavior tends to be more influenced by the location of dwellings relative to the main concentrations of facilities than by its distance to the closest facility. When living centrally you can obtain accessibility benefits through proximity rather than through mobility. I am somewhat more in doubt as to whether the finding in US studies of an "ideal" commute time of just over 16 minutes can be generalized independent of travel mode, job type, city type, etc. Anyway, in inner-city contexts, people use slower modes (walk, bike, and public transport that involves walking to and from stops) to a higher extent than in the suburbs, so 16 minutes may not be a very long trip (in $\mathrm{km}$ ) for inner-city dwellers.

I generally agree that the themes mentioned by Van Wee/Boarnet in paragraph 2.a.3 are important topics of future research. I have myself studied differences between different population groups (Næss 2006, chapter 9), and in particular gender differences (Næss 2008) but would like to go deeper into these issues, possibly in cross-national cooperation studies.

There are, however, still some issues where it seems like Van Wee/Boarnet and I do not agree. I will comment on these issues in the following.

\section{Implications of two-way causality between travel attitudes and residential location}

In paragraph 3.c, van Wee and Boarnet write: "The more households are able to self-select in neighborhoods they prefer based on their travel related attitudes, the larger the impact of ignoring RSS in studies into the impact of the built environment on travel behavior." This argument seems to rest on an assumption that even though there may be a two-way causal influence between travel attitudes and residential location, the influence of attitudes on residential location is stronger than the opposite influence. As Van Wee and Boarnet note (paragraph 2.d), it is very unlikely that travel attitudes are only explained by the "reversed causality." However, many of the attitude-related determinants of residential location are likely to be covered by traditional demographic and socioeconomic variables like age, gender, household composition, income, workforce participation, and education level. What I argue is that the travel-related residential preference attitudes for which the above-mentioned variables do not act as proxies, may well be balanced by influences (through spatial facilitation as well as local social norms) of built environment characteristics on travel attitudes. So although the demonstration of 
Built Environment (BE) impacts on travel does not mean that changes in $\mathrm{BE}$ will bring about equally large changes in travel (Van Wee and Boarnet, paragraph 2.b), this does not entail that the BE impacts on travel will necessarily be underestimated when controlling only for the traditional demographic and socioeconomic variables.

\section{$3 \quad$ Market-based or plan-led urban development}

Van Wee and Boarnet write in paragraph 2.b: "Even if the full effect of the built environment on travel behavior would result from RSS [residential self-selection], it still is relevant to build residential areas that match the wants and needs of people who prefer to travel by car, or those of people who prefer to walk or cycle, especially if there is a shortage of such areas."

Especially seen from a perspective of sustainable development, the claim that it is relevant to build residential areas that match the wants and needs of people who prefer to travel by car is problematic. Such car-oriented and low-density development not only increases the energy use and greenhouse gas emissions from transport, but also requires more energy for space heating and cooling per dwelling and represents larger encroachments on farmland, natural areas and biodiversity than more compact urban development. Car-oriented urban development also erodes the passenger base of public transport and will hence likely reduce its level of service, to the detriment of population groups who cannot afford or are for other reasons not able to drive a car.

Van Wee and Boarnet's support of the relevance of building residential areas to match the wants and needs of people who prefer to travel by car seems to be based on the presupposition that residential environments should be offered, satisfying the preferences of various market segments in terms of locations, density and composition of housing types. However, classical as well as neoclassical economic theory recognizes that market processes alone are not able to counteract externalities (i.e., social costs not included in the profitability analyses of the agents of the market, but shifted on to other people or the environment). Greenhouse gas emissions are an example of such externalities. Neither are sole market processes able to ensure a socially acceptable distribution of burdens and benefits. Thus, both the two key elements of the Brundtland Commission's (1987: 43) definition of a sustainable development- to meet vital needs and ensure an equitable distribution in time and space, and the condition of environmental sustainability—depend on planning and management by public authorities.

It has been argued that managing travel behavior through land use policy is limited by the market of households who prefer to locate in areas with high neighborhood accessibility (e.g., see Krizek 2003, p. 268). However, assuming that a given population will distribute themselves over the available residences in the region, construction of new suburban dwellings increases the number of people living in suburban areas (where accessibility to a large number of job opportunities and other facilities can only be obtained through high mobility), while growth in the number of inner-city dwellings increases the number of households living close to the city center (where high accessibility can be obtained without having to travel long distances). Channeling residential development to transport-reducing locations may or may not suppress market demand. Suppressing some demands is an inherently normal consequence of public planning, the justification of which in market societies is precisely to produce a different result from what would have occurred under unbridled market conditions (e.g., see Klosterman 1985). And as shown in the Oslo example, demands and preferences can be influenced by what is being supplied. There is considerable wisdom in the Aesop fable about the fox and the grapes: you may no longer feel a need for something that is anyway out of reach. (The fable's analogy with urban residential development is, however, not very accurate, since there would even in the absence of any further construction of single-family homes be a large number of existing single-family houses available on the market.) 


\section{Should we aim at quantification to facilitate cost-benefit analyses of land use?}

In paragraph 2.c, Van Wee and Boarnet write: "Especially if planning concepts that reduce motorized travel have major cons, such as higher costs, quantitative insights, preferably even expressed in monetary terms, into the pros and cons of these concepts are needed to understand how costs and benefits balance. This is particularly true if ex ante evaluations are based on Cost-Benefit Analysis (CBA)." But why should they be? Most countries have until now managed to do land use planning without having to rely on CBA, so it can hardly be necessary. There are also a number of highly problematic and contestable assumptions included in the CBA framework (Ackerman and Heinzerling 2004). The value of something for society is not reducible to the aggregate preferences of individuals, let alone the willingness of individuals to pay for it.

This insight is reflected in planning theory on the functions of and justification for intervention into market mechanism in the form of public-sector planning. According to Klosterman (1985), two of the main reasons for maintaining such planning are the need to provide public goods and to counteract externalities. In line with, among others, Tore Sager, I consider these tasks to be more adequately addressed through political deliberation and decision-making than through the counting of atomistic individual preferences (Sager 2002: 74-80 and 158-159; see also Arrow 1951). Moreover, for costbenefit analysis to produce accurate results, conditions of perfect market competition must exist. These conditions include, among other things, the requirement that humans act as fully informed, utilitymaximizing consumers. However, actual human behavior hardly conforms to this requirement (Ministry of Finance [Norway] 1997; Lohmann 1997; Archer 2000: 51-85). Along with instrumental rationality, human actions are guided by social rationality (Diesing 1962) as well as communicative rationality (Habermas 1984, 1987) and influenced by traditions and habits (Bourdieu 1984; Giddens 1979). They are also guided by ethical considerations which may well differ from the principle of individual utility maximizing. Neither is the presupposition of fully informed individuals met in real life. In particular, this applies to the ramifications of the various environmental impacts of the alternatives. For example, very few, if any, individuals are likely to be fully informed about the environmental changes and related impacts on societies and individuals resulting from greenhouse gas emissions.

Van Wee and Boarnet rightly point out that exact quantification — if at all possible —is often not needed for policy reasons. (In addition to their quoted study by Börjesson \& Eliasson, see also Sager $\&$ Ravlum 2005). I also agree in their argument that, even if exact quantifications of residential effects were possible, several other important uncertainties remain, such as estimates of the costs of policies, or the valuation of several effects. But why then carry out CBAs — and in particular: why carry out CBA for land-use decisions?

It seems like a main reason for the quest for exact quantification of the impacts of built environment characteristics on travel behavior is to provide input data for some sort of cost-benefit analysis of land use (whether monetized or not) —an assessment type that is hardly part of normal land use planning practice in any country today. Since the effects in question will be context-dependent, the translation of quantified effects found in research studies in other cities and/or at other times will necessarily introduce inaccuracy to the ex-ante assessments of the travel effects of a planned residential development. For example, even if (as is the case) studies of residential location and travel have been carried out in Greater Oslo and Greater Copenhagen, based on data collection in 1992 and 2001, respectively, and these studies have provided elasticities for the travel behavioral effects of the distance from the dwelling to the main city center and to the closest second-order center, there will be a relatively broad error margin if a planner in Helsinki wants to make some sort of interpolation and adaptation of these data to quantify the likely travel behavioral effects (with, say, 2020 as the time horizon) of two alternatives for residential 
development in the Finnish capital at different locations from the main city center and the closest second-order center. I am pretty sure that the uncertainty when adapting elasticities from other cities and other periods of time to ex-ante impact assessment is greater than the possible error committed if an empirical study is carried out with control only for demographic and socioeconomic characteristics of the respondents, but not for their travel-related residential preferences. At least the results from the Copenhagen and Hangzhou studies presented in my paper suggest so.

If reliable and accurate elasticities were to be produced, enabling planners to make ex-ante assessments of travel effects meeting the needs for meaningful cost-benefit analyses in land use planning, high-quality research studies of land use and travel would have to be conducted in every city, and since the world is constantly changing, the studies in each city would have to be carried out repeatedly to ensure updated elasticities.

While I consider quantification of built environment effects on travel to facilitate expansion of CBA regimes into the domain of land use planning a fruitless endeavor, I think inquiry into the magnitude of such effects in different city types, countries and among different population groups in order to improve the general information base for planning, or just for scientific curiosity, is meaningful and worthwhile. (I have myself tried to provide such planning-relevant information, among others in Chapter 12 in Næss 2006.) Getting a better grasp on the relationships between residential location, residential preferences and travel is a relevant part of such research. I think it is important that the attitudinal variables included in such research should be measured in such a way that the tradeoffs between conflicting residential preferences are taken into consideration. For example, a person might enjoy driving but still prefer to live in the city center rather than in a suburb—-for other reasons, for example being able to go to restaurants and bars in the evening without having to take a taxi home. The same person might still enjoy cruising with her car through rural and natural landscapes on leisure trips. And she might possibly not have sufficient income to live in the inner-city studio apartment she would prefer, so she ends up in a less expensive suburban house. If such a person is just being asked about travel attitudes, it would look as if this person had self-selected her into a suburban residential environment, while there in fact would have been mismatch between her residential preference and her actual place of living. 


\section{References}

Ackerman, F. \& Heinzerling, L. 2004. Priceless: On Knowing the Price of Everything and the Value of Nothing. New York: New Press.

Archer, M. 2000. Being Human. The Problem of Agency. Cambridge: Cambridge University Press.

Arrow, K. J. 1951. Social Choice and Individual Values. New York: John Wiley.

Bourdieu, P. 1984. Distinction: Critique of the Judgment of Taste. Cambridge: Harward University Press.

Bruegmann, R. 2005. Sprawl: A Compact History. Chicago: Chicago University Press.

Brundtland Commission (WCED). 1987. Our Common Future. Oxford and New York: Oxford University Press.

Diesing, P. 1962. Reason in Society: Five Types of Decisions and Their Social Conditions. Urbana, Illinois: University of Illinois Press.

Giddens, A. 1979. Central problems in social theory. Berkeley: University of California Press.

Habermas, J. 1984. The Theory of Communicative Action. Volume 1: Reason and the Rationalization of Society. London: Heinemann.

Habermas, J. 1987. The Theory of Communicative Action. Volume 2: Lifeworld and System: A Critique of Functionalist Reason. Boston, Massachusetts: Beacon Press.

Klosterman, R. E. 1985. Arguments for and against planning. Town Planning Review 56(1): 5-20.

Krizek, K. J. 2003. Residential relocation and changes in urban travel: Does neighborhood-scale urban form matter? Journal of the American Planning Association 69(3): 265-281.

Lohmann, L. 1997. Cost-Benefit Analysis: Whose Interest, Whose Rationality? London: The Corner House. http://www.thecornerhouse.org.uk/item.shtml?x=52011, accessed June 6, 2005.

Ministry of Finance (Norway). 1997. NOU 1997:27 Nytte-kostnadsanalyser (Costbenefit analyses). Oslo: Ministry of Finance.

Næss, P. 2006. Urban Structure Matters: Residential Location, Car Dependence and Travel Behaviour. London and New York: Routledge.

Næss, P. 2008. Gender differences in the influences of urban structure on daily-life travel. In Priya, T. \& T. Cresswell, eds. Gendered Mobilities, 173-192. Aldershot: Ashgate.

O'Toole, P. 2012. American Nightmare: How Government Undermines the Dream of Homeownership. Cato Institute.

Sager, T. 2002. Democratic Planning and Social Choice Dilemmas: Prelude to Institutional Planning Theory. Aldershot: Asghate.

Sager, T., and I. A. Ravlum. 2005. The political relevance of planners' analysis. The case of a parliamentary standing committee. Planning Theory 4(1): 33-65. 